\title{
Fraction Collector
}

National Cancer Institute

\section{Source}

National Cancer Institute. Fraction Collector. NCI Thesaurus. Code C80369.

An instrument that can collect the eluate from a chromatography column in discrete parts. 